\title{
Influência da deficiência de vitamina D sobre a disbiose intestinal: Uma revisão
}

\section{sistemática}

\author{
Influence of vitamin D deficiency on intestinal dysbiosis: A systematic review \\ Influencia de la deficiencia de vitamina D en la disbiosis intestinal: Una revisión sistemática
}

\author{
Ana Carolina Pereira de Araújo dos Anjos \\ ORCID: https://orcid.org/0000-0001-9985-9090 \\ Instituto de Educação Superior do Vale do Parnaíba, Brasil \\ E-mail: ana.araujo2081@gmail.com \\ Mirella Vidal Félix de Andrade \\ ORCID: https://orcid.org/0000-0003-3635-9317 \\ Instituto de Educação Superior do Vale do Parnaíba, Brasil \\ E-mail: mirellavidal5@ hotmail.com \\ Ana Caroline Maia Santos \\ ORCID: https://orcid.org/0000-0001-8735-1900 \\ Instituto de Educação Superior do Vale do Parnaíba, Brasil \\ E-mail: anacarolinemaia@outlook.com \\ Daniela Machado Bezerra \\ ORCID: https://orcid.org/0000-0003-3511-4836 \\ Instituto de Educação Superior do Vale do Parnaíba, Brasil \\ E-mail: danielamachadobezerra@hotmail.com \\ Manoel Aguiar Fenelon Júnior \\ ORCID: https://orcid.org/0000-0003-4096-806X \\ Instituto de Educação Superior do Vale do Parnaíba, Brasil \\ E-mail: manoel.fenelon@iesvap.edu.br \\ Joilson Ramos de Jesus \\ ORCID: https://orcid.org/0000-0002-8167-524X \\ Instituto de Educação Superior do Vale do Parnaíba, Brasil \\ E-mail: joilson.jesus@iesvap.edu.br
}

\begin{abstract}
Resumo
A microbiota intestinal influencia processos locais e sistêmicos importantes para o organismo, tendo em sua composição bactérias probióticas que auxiliam nos processos benéficos e bactérias comensais, que frequentemente causam infecções. O objetivo deste artigo é analisar a existência de uma relação entre a prevalência de bactérias patogênicas e inflamação intestinal quando os níveis plasmáticos se encontram deficientes de vitamina D. Para isso, foi realizada uma revisão de literatura com busca sistemática a fim de capturar as informações atuais sobre o tema, de forma a contribuir no direcionamento clínico. Como resultado da análise, foi verificado que a suficiência de vitamina D favorece a presença de probióticos e integridade da barreira intestinal, e que a deficiência está associada ao prevalecimento de patobiontes e inflamação intestinal. Sendo assim, manter níveis séricos suficientes de vitamina D favorecem a saúde intestinal, possibilitando um enterótipo dominado por probióticos, diminuição de marcadores inflamatórios e proteção da integridade da barreira intestinal.
\end{abstract}

Palavras-chave: Disbiose; Deficiência de vitamina D; Microbioma gastrointestinal.

\begin{abstract}
The intestinal microbiota influences important local and systemic processes for the organism, having in its composition probiotic bacteria that assist in the beneficial processes and commensal bacteria, which often cause infections. The aim of this article is to analyze the existence of a relationship between the prevalence of pathogenic bacteria and intestinal inflammation when plasma levels are deficient in vitamin D. For this, a literature review was carried out with a systematic search in order to capture the current information. on the topic, in order to contribute to the clinical direction. As a result of the analysis, it was found that vitamin D sufficiency favors the presence of probiotics and intestinal barrier integrity, and that deficiency is associated with the prevalence of pathobionts and intestinal inflammation. Therefore, maintaining sufficient serum levels of vitamin D favors intestinal health, enabling an enterotype dominated by probiotics, decreasing inflammatory markers and protecting the integrity of the intestinal barrier.
\end{abstract}

Keywords: Dysbiosis; Vitamin D deficiency; Gastrointestinal microbiome.

\section{Resumen}

La microbiota intestinal influye en procesos locales y sistémicos importantes para el organismo, teniendo en su 
composición bacterias probióticas que asisten en los procesos beneficiosos y bacterias comensales, que a menudo causan infecciones. El propósito de este artículo es analizar la existencia de una relación entre la prevalencia de bacterias patógenas y la inflamación intestinal cuando los niveles plasmáticos son deficientes en vitamina D. Para ello, se realizó una revisión de la literatura con una búsqueda sistemática con el fin de captar los datos actuales. información sobre el tema, con el fin de contribuir a la dirección clínica. Como resultado del análisis, se encontró que la suficiencia de vitamina D favorece la presencia de probióticos y la integridad de la barrera intestinal, y que la deficiencia se asocia con la prevalencia de patobiontes y la inflamación intestinal. Por tanto, mantener niveles séricos suficientes de vitamina $\mathrm{D}$ favorece la salud intestinal, posibilitando un enterotipo dominado por probióticos, disminuyendo los marcadores inflamatorios y protegiendo la integridad de la barrera intestinal.

Palabras clave: Disbiosis; Deficiencia de vitamina D; Microbioma gastrointestinal.

\section{Introdução}

A microbiota intestinal é estabelecida como um órgão do corpo, influenciando processos locais e sistêmicos como nutrição, suprimento de vitaminas, maturação da imunidade da mucosa e comunicação intestino-cérebro (Weiss \& Hennet, 2017). Dessa forma, necessita de adequada e estável composição celular, que no caso, consiste em 30-400 trilhões de microorganismos, incluindo bactérias (principalmente bactérias dos filos Bacteroidetes, Firmicutes, Actinobacteria e, em menor grau Proteobacteria), fungos e vírus que colonizam o intestino humano (de Oliveira et al., 2017).

O trato intestinal é estéril ao nascer, sendo colonizado e moldado por exposições ao longo da vida, como o parto (especialmente no parto normal, pelo contato direto com a microbiota fecal da mãe), fator genético, dieta, uso de antibióticos, idade gestacional e microorganismos do trato digestivo materno, atingindo a composição adulta aproximadamente aos 3 anos de idade (Yatsunenko et al., 2012). Nesse sentido, alterações no sistema imunológico e nos fatores expostos anteriormente podem levar à Disbiose, um estado de desequilíbrio entre o número de bactérias protetoras e agressoras, favorecendo uma endotoxemia metabólica e estado inflamatório crônico, pelo aumento da permeabilidade intestinal, que resulta na passagem ascendente de lipopolissacarídeo (LPS) para a circulação sistêmica (dos Santos Moraes et al., 2017)

A calprotectina fecal, um marcador de inflamação intestinal, mostrou estar inversamente relacionada à concentração sérica de vitamina D (VD) na doença de Crohn e na Doença Inflamatória Intestinal, despertando questionamentos sobre a existência de uma relação bidirecional entre vitamina D e a inflamação e microbiota intestinal (Naderpoor et al., 2019). Sigh et al., (2020) descreveu ainda o papel potencial da vitamina D como um modificador da microbiota intestinal em indivíduos saudáveis ao descobrir que após a suplementação com VD houve um aumento da diversidade geral da microbiota intestinal e, em particular, aumento da abundância relativa de Bacteroidetes (bactérias relacionadas a efeitos benéficos no organismo) e diminuição da abundância relativa de Firmicutes (bactérias muitas vezes associadas à infecções). Além do favorecimento de um enterótipo dominado por Bacteroides em relação ao Prevotella, sendo que este último é considerado um patobionte intestinal.

A vitamina D, apesar do nome, é considerada um hormônio esteroide que faz parte do grupo de secosteroides, derivado do 7-desidrocolesterol (7-DHC), tendo como metabólito ativo o 1 1 2,25 -diidroxi-vitamina D ou calcitriol; como precursores a vitamina D2 ou ergosterol, a vitamina D3 ou colecalciferol, 25-hidroxivitamina D [25 (OH) D] ou calcidiol, e alguns produtos de degradação. A maior parte da vitamina D é sintetizada de forma endógena nas camadas profundas da epiderme, da seguinte forma: a exposição da pele aos raios ultravioleta (UVB) permite o processo de clivagem fotoquímica do precursor cutâneo da vitamina D, o 7-desidrocolesterol, originando a pré-vitamina D3, que sofre um rearranjo molecular dependente de temperatura resultando na formação de vitamina D3 ou colecalciferol (Marques et al., 2010). São considerados fatores limitantes da produção de vitamina D a não exposição aos raios ultravioleta, o uso de protetores solares e o grau de pigmentação da pele, uma vez que peles negras apresentam menor penetração dos raios UVB (Melmed et al., 2015). Pequena parte pode ainda ser obtida através da dieta, a vitamina D3 (colecalciferol) é de origem animal e está presente no atum, bacalhau, sardinhas e salmão; a vitamina D2 (ergosterol) é de origem vegetal e também se encontra em fungos comestíveis como cogumelos shitake frescos e secos (Claudio Gonçalves de Castro, 2011). 
No sangue, o colecalciferol e ergosterol são transportados para o fígado principalmente pela proteína ligadora da vitamina D, ou transcalciferrina e uma pequena parte pela albumina, onde são hidroxilados por uma enzima citocromo P450-like no carbono 25 para formar calcidiol (25-OH-vitamina D) que é a forma de depósito da vitamina D. Por fim, o calcidiol é transportado pela DBP para os rins onde ocorre nova hidroxilação pela ação da enzima 1-alfa-hidroxilase, formando o calcitriol (1,25-OH-vitamina D), que é a forma metabolicamente ativa da vitamina D (Científico \& De Paula, 2016).

A vitamina D se liga aos receptores de vitamina D (VDR) e assim pode exercer suas funções biológicas, uma vez que eles regulam a transcrição do DNA em RNA, semelhante a outros membros da família de receptores nucleares. Por muito tempo o papel da vitamina D foi unicamente atribuído à regularização da fisiologia osteomineral, especialmente o metabolismo do cálcio. No entanto, os VDR são expressos por vários tipos de células, incluindo osteoblastos, osteoclastos, células hematopoiéticas, células epidérmicas, células pancreáticas, epitélio do intestino delgado, além de ser amplamente expresso na maioria das células imunológicas, incluindo monócitos, macrófagos, células dendríticas, células NK e linfócitos T e B (Marques et al., 2010). os efeitos anti-inflamatórios da vitamina D foram estudados extensivamente em diferentes condições de inflamação subaguda, aguda e crônica, como obesidade, diabetes e doença inflamatória intestinal . Nesse sentido, esse estudo objetivou revisar a literatura a fim de reunir informações atualizadas quanto à relação entre níveis debilitados de Vitamina D e as consequências disso sobre a disbiose intestinal, de forma a contribuir no direcionamento clínico.

\section{Metodologia}

O presente estudo trata-se de uma revisão sistemática de literatura, uma pesquisa de natureza quali-quantitativa (Estrela, 2018; Pereira et al., 2018). Para a sua elaboração foram seguidas etapas metodológicas nesta sequência: (I) elaboração da pergunta de pesquisa; (II) busca de evidências científicas; (III) seleção dos artigos; (IV) extração dos dados; (V) avaliação da qualidade metodológica; (VI) síntese dos dados; (VII) avaliação dos níveis evidências; e (VIII) redação e publicação dos resultados.

A pesquisa de registros científicos teve como base a questão norteadora: "Níveis baixos de vitamina D favorecem o desenvolvimento de disbiose intestinal?", formulada a partir do uso da estratégia do acrônimo PICO (Population, Intervention, Comparison, Outcome), que por sua vez foi definido com base nos objetivos do presente estudo como:

P: Pacientes e animais com níveis plasmáticos deficientes de vitamina D.

I: Suplementação com vitamina D.

C: Dieta com restrição de vitamina D.

O: Disbiose intestinal.

Com intuito de capturar artigos que apresentassem em seus desenhos de estudo correlação entre disbiose intestinal e a deficiência de vitamina D. As informações foram obtidas a partir de buscas feitas no período de 2008 a 2020 nas bases de dados Literatura Latino-americana e do Caribe em Ciências da Saúde (LILACS), PubMed e Scientific Electronic Library Online (Scielo), utilizando como descritores os termos "Disbiose", "Deficiência de vitamina D" e "Microbioma gastrointestinal", identificados nos Descritores em Ciências da Saúde (DECS). A pesquisa foi realizada com os descritores em inglês no Pubmed e em português e espanhol no Scielo e no LILACS. A busca dos artigos foi realizada em cada uma das bases de dados seguindo os seguintes passos: inicialmente a busca foi feita utilizando os três descritores isoladamente e, depois, em combinação de dois e três termos, usando o operador booleano "and". Foram incluídos estudos realizados em humanos e animais, que possuíam boa confiabilidade metodológica e abordavam a relação entre a vitamina D e a disbiose intestinal. Já os critérios de exclusão do 
trabalho foram os artigos com tempo de publicação superior há 15 anos, artigos com amostras incompatíveis, revisões de literatura e revisões sistemáticas. Assim, foram encontrados 18 artigos aptos para serem abordados, como mostra a Figura 1.

Figura 1. Fluxograma dos passos metodológicos para seleção dos estudos.
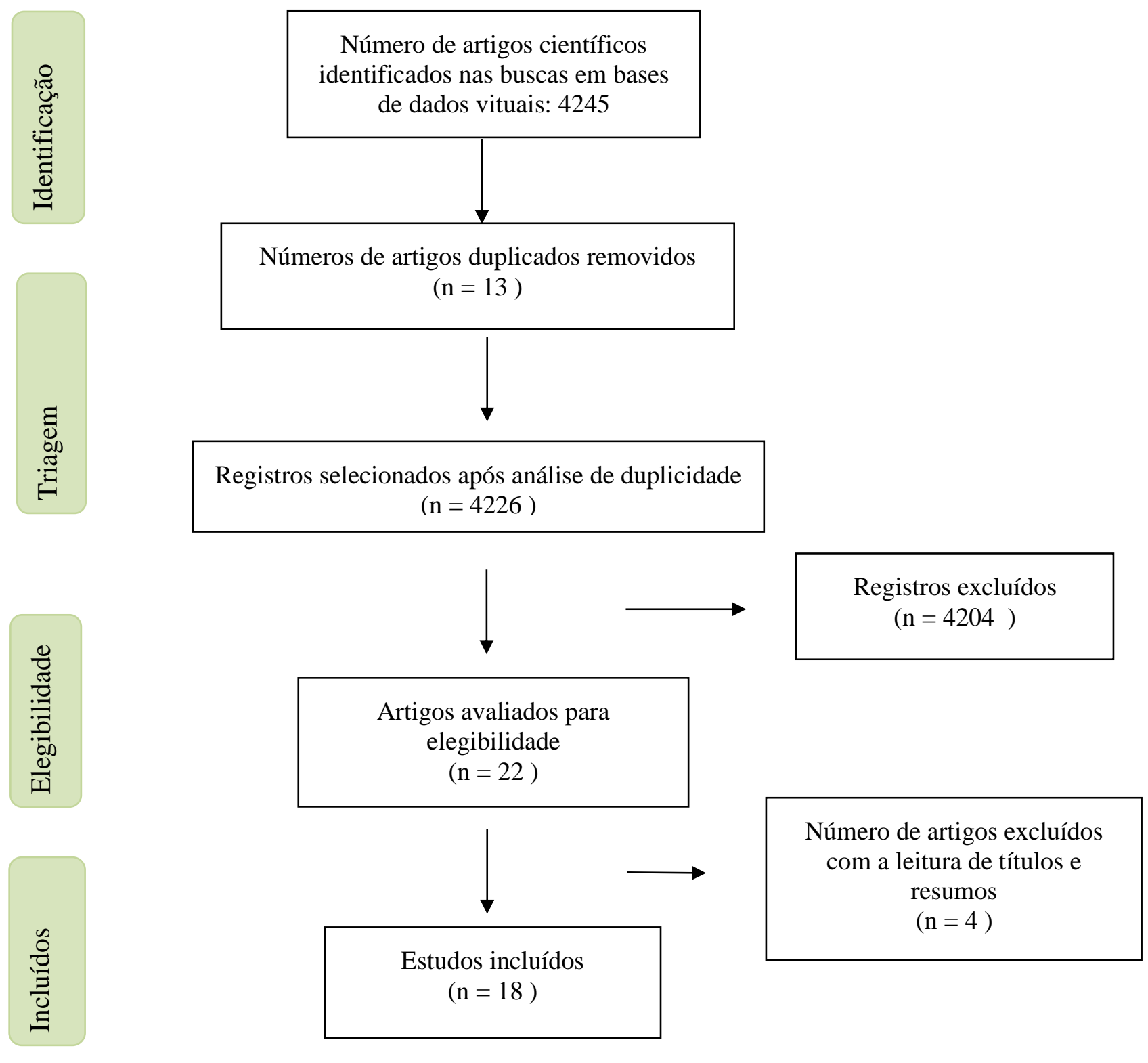

Fonte: Autores (2021).

\section{Resultados e discussão}

Inicialmente, foram obtidos 4.245 artigos: 4234 no PubMed, 5 na Scielo e 6 na Lilacs. Depois de considerar os critérios de exclusão e análise dos títulos, restaram 22 artigos do PubMed, 0 da Scielo e 0 da Lilacs: 22 no total, que foram selecionados para leitura completa dos resumos. Quando o resumo mostrou-se pertinente ao objetivo da pesquisa, o trabalho foi lido na íntegra. Por fim, foram selecionados 18 textos do PubMed, 0 da Scielo e 0 da Lilacs, reduzindo o corpus a 18 artigos científicos, como mostra o Quadro 1.

Os 18 artigos estavam divididos da seguinte forma: dez estudos feitos em humanos e oito em animais, sendo oito ensaios clínicos controlados, dois ensaios clínicos não controlados, seis ensaios clínicos randomizados e controlados, e dois estudos 
experimentais in vivo, como é mostrado no Quadro 2.

Quadro 1. Número de artigos por base de dados.

\begin{tabular}{|l|l|l|}
\hline \multicolumn{1}{|c|}{$\begin{array}{c}\text { Base de } \\
\text { dados }\end{array}$} & \multicolumn{1}{|l|}{ Encontrados } & Selecionados \\
\hline PubMed & 4234 artigos & 18 artigos \\
\hline Scielo & 5 artigos & Nenhum artigo \\
\hline Lilacs & 6 artigos & Nenhum artigo \\
\hline
\end{tabular}

Fonte: Autores (2021).

Quadro 2. Distribuição dos artigos segundo autores/ano de publicação, delineamento, nível de evidência e principais resultados.

\begin{tabular}{|c|c|c|c|c|}
\hline Título da obra & Autor/Ano & Delineamento & $\begin{array}{l}\text { Nível de } \\
\text { evidência }\end{array}$ & Resultados principais \\
\hline $\begin{array}{l}1 \\
\text { O efeito da vitamina D } \\
\text { na inflamação intestinal } \\
\text { e na microbiota fecal em } \\
\text { pacientes com colite } \\
\text { ulcerativa }\end{array}$ & $\begin{array}{l}\text { Garg et al., } \\
2018\end{array}$ & $\begin{array}{l}\text { Ensaio clínico } \\
\text { controlado }\end{array}$ & $\begin{array}{l}\text { Nível III - } \\
\text { ensaios } \\
\text { clínicos bem } \\
\text { delineados, } \\
\text { sem } \\
\text { randomização }\end{array}$ & $\begin{array}{l}\text { A reposição de vitamina D em uma dose de } 40.000 \text { UI } \\
\text { semanalmente durante } 8 \text { semanas reduziu marcadores } \\
\text { de inflamação intestinal, como a calprotectina fecal em } \\
\text { pacientes com UC ativa com deficiência de vitamina D. } \\
\text { Isso foi associado a um aumento na Enterobacteriacae, } \\
\text { mas no geral não houve mudanças significativas na } \\
\text { diversidade da microbiota. }\end{array}$ \\
\hline $\begin{array}{l}2 \\
\text { O efeito do consumo } \\
\text { diário de diferentes } \\
\text { doses de pão Lavash } \\
\text { fortificado versus pão } \\
\text { simples no status de } \\
\text { vitamina D sérica, } \\
\text { composição corporal, } \\
\text { biomarcadores } \\
\text { metabólicos e } \\
\text { inflamatórios e } \\
\text { microbiota intestinal em } \\
\text { adultos aparentemente } \\
\text { saudáveis: protocolo de } \\
\text { estudo de um ensaio } \\
\text { clínico randomizado }\end{array}$ & $\begin{array}{l}\text { Tangestani; } \\
\text { Kurosh; } \\
\text { Shab- } \\
\text { Bidar., } \\
2019\end{array}$ & $\begin{array}{l}\text { Ensaio clínico } \\
\text { duplo-cego, } \\
\text { randomizado e } \\
\text { controlado }\end{array}$ & $\begin{array}{l}\text { Nível II - } \\
\text { evidências } \\
\text { derivadas de } \\
\text { pelo menos } \\
\text { um ensaio } \\
\text { clínico } \\
\text { randomizado }\end{array}$ & $\begin{array}{l}\text { Usar o pão, alimento consumido diariamente por } \\
\text { diversas populações, fortificado com vitamina D, a fim } \\
\text { de melhorar os níveis séricos de vitamina D e } \\
\text { determinar o efeito da vitamina D na composição } \\
\text { corporal, biomarcadores metabólicos e inflamatórios e } \\
\text { microbiota intestinal em adultos aparentemente } \\
\text { saudáveis }\end{array}$ \\
\hline $\begin{array}{l}3 \\
\text { A suplementação de } \\
\text { vitamina D3 em bolus } \\
\text { semanal afeta a } \\
\text { microbiota intestinal e } \\
\text { das vias aéreas em } \\
\text { adultos com fibrose } \\
\text { cística: um ensaio } \\
\text { clínico duplo-cego, } \\
\text { randomizado e } \\
\text { controlado por placebo }\end{array}$ & $\begin{array}{l}\text { Kanhere et } \\
\text { al., } 2018\end{array}$ & $\begin{array}{l}\text { Ensaio clínico } \\
\text { randomizado } \\
\text { controlado }\end{array}$ & $\begin{array}{l}\text { Nível II - } \\
\text { evidências } \\
\text { derivadas de } \\
\text { pelo menos } \\
\text { um ensaio } \\
\text { clínico } \\
\text { randomizado }\end{array}$ & $\begin{array}{l}\text { Após as } 12 \text { semanas, houve diferença na microbiota de } \\
\text { indivíduos que foram randomizados para tomar uma } \\
\text { vez por semana } 50.000 \text { UI de vitamina } \\
\text { D } 3 \text { em comparação com indivíduos randomizados para } \\
\text { placebo. As gamaproteobactérias, espécies } \\
\text { potencialmente patogênicas, foram enriquecidas na } \\
\text { deficiência de vitamina D, além do aumento de } \\
\text { Bacteroides na microbiota das vias aéreas. } \\
\text { Lactococcus, bactérias associadas à saúde } \\
\text { intestinal, foram enriquecidos na presença da vitamina } \\
\text { D3. }\end{array}$ \\
\hline $\begin{array}{l}4 \\
\text { Correlação entre o status } \\
\text { da vitamina D e a } \\
\text { microbiota intestinal em }\end{array}$ & $\begin{array}{l}\text { Chen et al., } \\
2020\end{array}$ & $\begin{array}{l}\text { Ensaio clínico } \\
\text { controlado }\end{array}$ & $\begin{array}{l}\text { Nível III - } \\
\text { ensaios } \\
\text { clínicos bem } \\
\text { delineados, } \\
\text { sem }\end{array}$ & $\begin{array}{l}\text { Não houve diferença na diversidade alfa e beta da } \\
\text { microbiota entre os grupos suficientes, deficientes e } \\
\text { insuficientes de } 25(\mathrm{OH}) \text { D. No entanto, a abundância } \\
\text { de Proteobacteria foi maior no grupo deficiente de } \\
\text { vitamina D (<30nmol/L) e Actnomycete foi maior no }\end{array}$ \\
\hline
\end{tabular}




\begin{tabular}{|c|c|c|c|c|}
\hline $\begin{array}{l}\text { pacientes com doença } \\
\text { inflamatória intestinal }\end{array}$ & & & randomização & grupo suficiente de vitamina D (>50nmol/L). \\
\hline $\begin{array}{l}5 \\
\text { Efeito da suplementação } \\
\text { de vitamina D na } \\
\text { microbiota fecal: um } \\
\text { ensaio clínico } \\
\text { randomizado }\end{array}$ & $\begin{array}{l}\text { Naderpoor } \\
\text { et al., } 2019\end{array}$ & $\begin{array}{l}\text { Ensaio clínico } \\
\text { de grupo } \\
\text { paralelo, duplo- } \\
\text { cego, } \\
\text { randomizado e } \\
\text { controlado }\end{array}$ & $\begin{array}{l}\text { Nível II - } \\
\text { evidências } \\
\text { derivadas de } \\
\text { pelo menos } \\
\text { um ensaio } \\
\text { clínico } \\
\text { randomizado }\end{array}$ & $\begin{array}{l}\text { Participantes com IMC }>25 \mathrm{~kg} / \mathrm{m}^{2} \text { e sem comorbidades } \\
\text { receberam uma dose de ataque de } 100.000 \text { unidades } \\
\text { internacionais (UI) de colecalciferol por via oral } \\
\text { seguida de } 4000 \text { UI / dia (quatro cápsulas) por } 16 \\
\text { semanas ou placebo correspondente. Foi encontrado um } \\
\text { aumento da abundância } \\
\text { de Lachnospira e Coprococcus e uma diminuição da } \\
\text { abundância de Blautia, } \\
\text { Clostridiaceae e Ruminococcus nos indivíduos com } \\
\text { maiores concentrações séricas de } 25(\mathrm{OH}) \text { D. }\end{array}$ \\
\hline $\begin{array}{l}6 \\
\text { Efeito e mecanismo da } \\
\text { vitamina } D \text { no } \\
\text { desenvolvimento de } \\
\text { câncer colorretal com } \\
\text { base no distúrbio da } \\
\text { flora intestinal }\end{array}$ & $\begin{array}{l}\text { Zhou et al., } \\
2020\end{array}$ & $\begin{array}{l}\text { Ensaio clínico } \\
\text { randomizado, } \\
\text { controlado }\end{array}$ & $\begin{array}{l}\text { Nível II - } \\
\text { evidências } \\
\text { derivadas de } \\
\text { pelo menos } \\
\text { um ensaio } \\
\text { clínico } \\
\text { randomizado }\end{array}$ & $\begin{array}{l}\text { A deficiência de vitamina D piorou a deterioração da } \\
\text { inflamação e do câncer intestinal em camundongos com } \\
\text { câncer colorretal, enquanto a condição geral dos } \\
\text { camundongos melhorou após a suplementação de } \\
\text { vitamina D (com } 1500 \text { ou } 3000 \text { IU vitamin D3/kg). A } \\
\text { vitamina D tem um efeito regulador de probióticos } \\
\text { intestinais e ajuda na integridade da barreira do cólon, } \\
\text { que é mediada por Akkermansia muciniphila por meio } \\
\text { da expressão de acilgliceróis. }\end{array}$ \\
\hline $\begin{array}{l}7 \\
\text { Dieta rica em gordura } \\
\text { com restrição de } \\
\text { vitamina D regula } \\
\text { negativamente a } \\
\text { expressão de isozimas } \\
\text { de fosfatase alcalina } \\
\text { intestinal em ratos } \\
\text { ovariectomizados }\end{array}$ & $\begin{array}{l}\text { Nakaoka et } \\
\text { al., } 2018\end{array}$ & $\begin{array}{l}\text { Experimental in } \\
\text { vivo, controlado } \\
\text { e não } \\
\text { randomizado }\end{array}$ & $\begin{array}{l}\text { Nível III - } \\
\text { ensaios } \\
\text { clínicos bem } \\
\text { delineados, } \\
\text { sem } \\
\text { randomização }\end{array}$ & $\begin{array}{l}\text { A dieta rica em gordura com restrição de vitamina D } \\
\text { regulou negativamente as expressões de mRNA } \\
\text { das isozimas fosfatase alcalina intestinal (IAP) no } \\
\text { duodeno de modelos animais menopausados. A IAP } \\
\text { controla a inflamação induzida por endotoxinas } \\
\text { bacterianas ao desfosforilar o lipopolissacarídeo, } \\
\text { sendo um fator de defesa da mucosa intestinal. }\end{array}$ \\
\hline $\begin{array}{l}8 \\
\text { A deficiência de } \\
\text { vitamina D altera o } \\
\text { microbioma intestinal, } \\
\text { reduzindo a produção de } \\
\text { vitamina B no intestino. } \\
\text { A falta de ácido } \\
\text { pantotênico resultante } \\
\text { afeta negativamente o } \\
\text { sistema imunológico, } \\
\text { produzindo um estado } \\
\text { "pró-inflamatório" } \\
\text { associado à } \\
\text { aterosclerose e } \\
\text { autoimunidade }\end{array}$ & $\begin{array}{l}\text { Gominak, } \\
2016\end{array}$ & $\begin{array}{l}\text { Ensaio clínico } \\
\text { não controlado }\end{array}$ & $\begin{array}{l}\text { Nível III - } \\
\text { ensaios } \\
\text { clínicos bem } \\
\text { delineados, } \\
\text { sem } \\
\text { randomização }\end{array}$ & $\begin{array}{l}\text { Os participantes com queixas neurológicas, problemas } \\
\text { no sono e sintomas de síndrome do intestino irritável } \\
\text { (SII), após suplementação com doses mínimas } \\
\text { recomendadas das } 8 \text { vitaminas B por três meses, } \\
\text { associada a doses individuais de vitamina D } \\
\text { com intuito de manter níveis sanguíneos de } 60-80 \mathrm{ng} / \mathrm{ml} \\
\text { de forma contínua, obtiveram em sua maioria a } \\
\text { resolução completa de todos os sintomas de SII ao final } \\
\text { dos três meses. A suplementação com vitamina D foi } \\
\text { mantida e retirada as doses de vitaminas B. Houve } \\
\text { também melhora de algumas queixas de sono e dor. }\end{array}$ \\
\hline $\begin{array}{l}9 \\
\text { A administração de } \\
\text { vitamina D leva a uma } \\
\text { mudança na composição } \\
\text { bacteriana intestinal em } \\
\text { pacientes com doença de } \\
\text { Crohn, mas não em } \\
\text { controles saudáveis }\end{array}$ & $\begin{array}{l}\text { Shaffler et } \\
\text { al., } 2018\end{array}$ & $\begin{array}{l}\text { Ensaio clínico } \\
\text { controlado }\end{array}$ & $\begin{array}{l}\text { Nível III - } \\
\text { ensaios } \\
\text { clínicos bem } \\
\text { delineados, } \\
\text { sem } \\
\text { randomização }\end{array}$ & $\begin{array}{l}\text { Após administração de colecalciferol 20.000UI por } 4 \\
\text { semanas em dias alternados, os pacientes com Doença } \\
\text { de Chron obtiveram alta abundância de algumas } \\
\text { espécies como Alistipes, Barnesiella, Roseburia, } \\
\text { Anaerotruncus, Subdoligranulum e um } \\
\text { Ruminococaceae. Apesar das comunidades microbianas } \\
\text { mudarem significativamente, um aumento adicional no } \\
\text { nível de vitamina D foi associado a uma reversão desse } \\
\text { efeito, causando diminuição da riqueza bacteriana. } \\
\text { No entanto, não houve mudanças nos pacientes } \\
\text { controles saudáveis. }\end{array}$ \\
\hline $\begin{array}{l}10 \\
\text { O papel potencial da } \\
\text { suplementação de } \\
\text { vitamina D como um }\end{array}$ & Singh, 2020 & $\begin{array}{l}\text { Ensaio clínico } \\
\text { não controlado }\end{array}$ & $\begin{array}{l}\text { Nível III - } \\
\text { ensaios } \\
\text { clínicos bem } \\
\text { delineados, } \\
\text { sem }\end{array}$ & $\begin{array}{l}\text { A suplementação de vitamina D aumentou a } \\
\text { diversidade geral da microbiota intestinal e, em } \\
\text { particular, aumentou a abundância relativa } \\
\text { de Bacteroidetes e diminuiu a abundância relativa }\end{array}$ \\
\hline
\end{tabular}




\begin{tabular}{|c|c|c|c|c|}
\hline $\begin{array}{l}\text { modificador da } \\
\text { microbiota intestinal em } \\
\text { indivíduos saudáveis }\end{array}$ & & & randomização & $\begin{array}{l}\text { de Firmicutes. } \\
\text { Houve também aumento dos } \\
\text { filos Verrucomicrobia e Actinobacteria. Nesse sentido, } \\
\text { também favoreceu um enterótipo dominado por } \\
\text { Bacteroides em relação ao Prevotella, sendo que este } \\
\text { último é considerado um patobionte intestinal. }\end{array}$ \\
\hline $\begin{array}{l}11 \\
\text { Sinalização de vitamina } \\
\text { D através da indução de } \\
\text { defensinas celulares } \\
\text { panetíticas mantém a } \\
\text { microbiota intestinal e } \\
\text { melhora os distúrbios } \\
\text { metabólicos e a } \\
\text { esteatose hepática em } \\
\text { modelos animais }\end{array}$ & $\begin{array}{l}\text { Su et al., } \\
2016\end{array}$ & $\begin{array}{l}\text { Ensaio clínico } \\
\text { randomizado }\end{array}$ & $\begin{array}{l}\text { Nível II - } \\
\text { evidências } \\
\text { derivadas de } \\
\text { pelo menos } \\
\text { um ensaio } \\
\text { clínico } \\
\text { randomizado }\end{array}$ & $\begin{array}{l}\text { Camundongos alimentados com dieta gordurosa+vit } \\
\text { D(HFD) ou dieta controle sem vit D (VDD) } \\
\text { desenvolveram esteatose hepática moderada. Em } \\
\text { contraste, os camundongos HFD + VDD } \\
\text { desenvolveram esteatose hepática grave. O grau de } \\
\text { esteatose foi associado à deficiência de } 25 \text {-OH } \\
\text { VD } 3 \text { plasmático, assim como o grau de inflamação } \\
\text { sistêmica e da integridade do revestimento da mucosa } \\
\text { ileal. } \\
\text { Houve crescimento de H. Hepaticus nos grupos } \\
\text { deficientes de vitamina D e supressão de } A \text {. } \\
\text { Muciniphila. }\end{array}$ \\
\hline $\begin{array}{l}12 \\
\text { A vitamina D regula o } \\
\text { microbioma intestinal e } \\
\text { protege camundongos } \\
\text { da colite induzida por } \\
\text { sulfato de sódio } \\
\text { dextrano } \\
\text { A vitamina D regula o } \\
\text { microbioma intestinal e } \\
\text { protege camundongos } \\
\text { da colite induzida por } \\
\text { sulfato de sódio dext }\end{array}$ & $\begin{array}{l}\text { Ooi et al., } \\
2013\end{array}$ & $\begin{array}{l}\text { Ensaio clínico } \\
\text { controlado }\end{array}$ & $\begin{array}{l}\text { Nível III - } \\
\text { ensaios } \\
\text { clínicos bem } \\
\text { delineados, } \\
\text { sem } \\
\text { randomização }\end{array}$ & $\begin{array}{l}\text { Os dados sugerem que, na ausência do VDR ou na } \\
\text { capacidade de produzir } 1,25(\mathrm{OH})_{2} \mathrm{D}_{3} \text {, a inflamação } \\
\text { desregulada do intestino resulta em um ambiente que } \\
\text { suporta a expansão de bactérias no filo } \\
\text { Proteobacteria. A expansão do filo Proteobacteria } \\
\text { (incluindo os membros da família Helicobacteraceae) } \\
\text { compete com os membros benéficos dos filos } \\
\text { Firmicutes e Deferribacteres. Desse modo, a } \\
\text { integridade epitelial é prejudicada, ocorre disbiose, } \\
\text { aumento da inflamação e colite experimental mais } \\
\text { grave. }\end{array}$ \\
\hline $\begin{array}{l}13 \\
\text { Impacto do déficit de } \\
\text { vitamina D no } \\
\text { microbioma intestinal de } \\
\text { rato } \\
\text { Impacto do déficit de } \\
\text { vitamina D no } \\
\text { microbioma intestinal de } \\
\text { rato }\end{array}$ & $\begin{array}{l}\text { Robles- } \\
\text { Vera et al., } \\
2019\end{array}$ & $\begin{array}{l}\text { Ensaio clínico } \\
\text { randomizado, } \\
\text { controlado }\end{array}$ & $\begin{array}{l}\text { Nível II - } \\
\text { evidências } \\
\text { derivadas de } \\
\text { pelo menos } \\
\text { um ensaio } \\
\text { clínico } \\
\text { randomizado }\end{array}$ & $\begin{array}{l}\text { Os animais foram alocados em dois grupos, um com } \\
\text { dieta padrão adicionada de } 1.500 \text { UI / kg de } \\
\text { colecalciferol e um com uma dieta personalizada livre } \\
\text { de vitamina D, por sete semanas. houve um aumento } \\
\text { na família Enterobacteriaceae com aumentos } \\
\text { significativos em seus gêneros } \\
\text { associados Escherichia, Candidatus blochmannia e } \\
\text { Enterobacter, um aumento em Prevotellaceae e seu } \\
\text { gênero Prevotella e uma diminuição na família } \\
\text { Odoribacteraceae e seu gênero Butyricimonas no grupo } \\
\text { livre de vitamina D. Não houve mudanças } \\
\text { significativas na } \\
\text { diversidade } \alpha \text { e } \beta \text {. }\end{array}$ \\
\hline $\begin{array}{l}14 \\
\text { A deficiência de } \\
\text { vitamina D predispõe à } \\
\text { disfunção de barreira } \\
\text { induzida por } \\
\text { Escherichia coli } \\
\text { invasiva aderente e lesão } \\
\text { colônica experimental }\end{array}$ & $\begin{array}{l}\text { Assa et al., } \\
2015\end{array}$ & $\begin{array}{l}\text { Ensaio clínico } \\
\text { controlado }\end{array}$ & $\begin{array}{l}\text { Nível III - } \\
\text { ensaios } \\
\text { clínicos bem } \\
\text { delineados, } \\
\text { sem } \\
\text { randomização }\end{array}$ & $\begin{array}{l}1,25(\mathrm{OH}) \text { 2D3 atenuou a permeabilidade paracelular } \\
\text { induzida pela infecção por Escherichia coli invasiva } \\
\text { aderente e redistribuição de proteínas de junção. } \\
\text { A deficiência de vitamina D predispõe a alterações na } \\
\text { função da barreira, criando assim um ambiente que } \\
\text { promove colonização de patógenos do trato intestinal e } \\
\text { posterior exacerbação } \\
\text { da resposta inflamatória. }\end{array}$ \\
\hline $\begin{array}{l}15 \\
\text { A falta de receptor de } \\
\text { vitamina D causa } \\
\text { disbiose e altera as } \\
\text { funções do microbioma } \\
\text { intestinal murino }\end{array}$ & $\begin{array}{l}\text { Jin et al., } \\
2015\end{array}$ & $\begin{array}{l}\text { Estudo } \\
\text { experimental in } \\
\text { vivo }\end{array}$ & $\begin{array}{l}\text { Nível III - } \\
\text { ensaios } \\
\text { clínicos bem } \\
\text { delineados, } \\
\text { sem } \\
\text { randomização }\end{array}$ & $\begin{array}{l}\text { No nível taxonômico, a linhagem de Lactobacillales- } \\
\text { a- Lactobacillus foi diminuída em amostras fecais } \\
\text { de } V d r^{-1} \text {. Em camundongos } V d r^{-1-}, \text { Lactobacillus foi } \\
\text { depletado nas fezes em comparação com as fezes cecal, } \\
\text { enquanto Tannerella, } \\
\text { Odoribacter, Porphyromonas, Butyricimonas, Bactero } \\
\text { ides, Prevotella, Rikenella, Pedobacter e Limibacter } \mathrm{f}\end{array}$ \\
\hline
\end{tabular}




\begin{tabular}{|c|c|c|c|c|}
\hline & & & & oram enriquecidos. \\
\hline $\begin{array}{l}16 \\
\text { Novo papel do receptor } \\
\text { de vitamina D na } \\
\text { manutenção da } \\
\text { integridade da barreira } \\
\text { da mucosa intestinal }\end{array}$ & $\begin{array}{l}\text { Kong et al., } \\
2008\end{array}$ & $\begin{array}{l}\text { Ensaio clínico } \\
\text { controlado }\end{array}$ & $\begin{array}{l}\text { Nível III - } \\
\text { ensaios } \\
\text { clínicos bem } \\
\text { delineados, } \\
\text { sem } \\
\text { randomização }\end{array}$ & $\begin{array}{l}\text { Camundongos que possuíam VDR (VDR +/+) foram } \\
\text { resistentes à colite induzida, enquanto os que não } \\
\text { possuíam (VDR -/-) deselvolveram diarreia grave, } \\
\text { sangramento retal, perda de peso corporal e morte após } \\
2 \text { semanas. O estudo verificou graves lesões nas } \\
\text { junções epiteliais do intestino nos camundongos que } \\
\text { não possuíam expressão de VDR. }\end{array}$ \\
\hline $\begin{array}{l}17 \\
\text { A 25-hidroxilação } \\
\text { prejudicada da vitamina } \\
\text { D na lesão hepática } \\
\text { suprime as defensinas } \\
\text { das células Paneth } \\
\text { intestinais, levando à } \\
\text { disbiose intestinal e } \\
\text { fibrogênese hepática }\end{array}$ & $\begin{array}{l}\text { Wu et al., } \\
2020\end{array}$ & $\begin{array}{l}\text { Ensaio clínico } \\
\text { controlado }\end{array}$ & $\begin{array}{l}\text { Nível III - } \\
\text { ensaios } \\
\text { clínicos bem } \\
\text { delineados, } \\
\text { sem } \\
\text { randomização }\end{array}$ & $\begin{array}{l}\text { Lesão hepática e fibrose estão associadas à deficiência } \\
\text { de vitamina D (VD) devido à diminuição da } 25- \\
\text { hidroxilação hepática da VD no fígado. Insuficiência da } \\
\text { sinalização de VD pode prejudicar a imunidade e } \\
\text { integridade inata intestinal, incluindo menor regulação } \\
\text { das funções das células Paneth, levando ao aumento da } \\
\text { translocação bacteriana para endotoxemia e disbiose } \\
\text { intestinal, que pode consequentemente promover a } \\
\text { fibrogênese hepática. O aumento da permeabilidade } \\
\text { intestinal na lesão hepática e fibrose foi melhorado pela } \\
\text { administração repetida de DEFA5, que, } \\
\text { consequentemente, também reduziu a endotoxina } \\
\text { plasmática. Bacteriodetes no nível de filos foram } \\
\text { diminuidos em camundongos com lesão hepática. }\end{array}$ \\
\hline $\begin{array}{l}18 \\
\text { A deficiência de } \\
\text { vitamina D promove } \\
\text { disfunção da barreira } \\
\text { epitelial e inflamação } \\
\text { intestinal }\end{array}$ & $\begin{array}{l}\text { Assa et al., } \\
2014\end{array}$ & $\begin{array}{l}\text { Ensaio clínico } \\
\text { controlado }\end{array}$ & $\begin{array}{l}\text { Nível III - } \\
\text { ensaios } \\
\text { clínicos bem } \\
\text { delineados, } \\
\text { sem } \\
\text { randomização }\end{array}$ & $\begin{array}{l}\text { Camundongos foram divididos em } 4 \text { grupos, sendo dois } \\
\text { infectados por } C \text {. Rodentium (um grupo deficiente e } \\
\text { outro suficiente de vitamina D) e dois não infectados } \\
\text { (um decifiente e outro eficiente de vitamina D). } \\
\text { A infecção por } C \text {. rodentium em animais aumentou a } \\
\text { permeabilidade intestinal e hiperplasia de criptas no } \\
\text { grupo de pessoas suficientes de vitamina } \mathrm{D} \text {, no entanto, } \\
\text { o aumento foi significativamente maior no grupo } \\
\text { deficiente de vitamina D. A deficiência de vitamina D } \\
\text { resultou em níveis mais elevados de citocinas pró- } \\
\text { inflamatórias e antiinflamatórias em ambos os grupos } \\
\text { de estudo com deficiência de vitamina } \mathrm{D} \text { (sem e com } \\
\text { infecção ), em comparação com animais com vitamina } \\
\text { D suficiente. No grupo de camundongos infectados } \\
\text { com deficiência de vitamina D, houve um aumento na } \\
\text { abundância de Actinobacteria e Gammaproteobacteria. }\end{array}$ \\
\hline
\end{tabular}

Fonte: Autores (2021).

\subsection{Influência da vitamina D na composição da microbiota gastrointestinal}

Todos os registros analisados apresentaram um aumento de filos, famílias, gêneros ou espécies de bactérias benéficas/probióticas e uma diminuição de bactérias patogênicas nos casos de suplementação com vitamina $\mathrm{D}$, ou o inverso, nos casos de níveis deficientes de vitamina D ou alterações no receptor de vitamina D (VDR), a exemplo do estudo de Kanhere et al. (2018), onde após os pacientes serem suplementados com 50.000 UI de vitamina D3 por 12 semanas, houve um enriquecimento de Lactococcus, bactérias associadas à saúde intestinal, corroborando relatos de estudo realizado por Jin et al. (2015), que apresentou diminuição de Lactobacillus nas amostras fecais de camundongos com ausência de receptor de vitamina $\mathrm{D}\left(V d r^{-1-}\right)$.

Além disso, 95\% dos registros eleitos para compor a presente revisão, que analisaram a diversidade microbiana não relataram modificações significativas da mesma, como o estudo de Robles-Vera et al. (2019), que verificou que uma dieta livre de vitamina D por sete semanas não alterou de forma estatisticamente significativa a diversidade e riqueza microbiana quando comparada a uma dieta padrão. No entanto, relatou que houve um aumento da família Enterobacteriaceae e seus gêneros Escherichia, Enterobacter, e da espécie Candidatus blochmannia, que fazem parte da classe Gammaproteobacteria e muitas vezes causam infecções no trato gastrointestinal, urinário e respiratório; além da bactéria oportunista Prevotella, frequentemente 
encontrada em infecções. Da mesma forma, Naderpoor et al. (2019) descreveu que não houve mudanças importantes na diversidade microbiana, porém, participantes que atingiram uma concentração de 25 (OH) D acima de 75 nmol / L no acompanhamento tiveram uma abundância maior do gênero Coprococcus (probióticos) e menor abundância do gênero Ruminococcus (associadas a alguns tipos de infecções) em comparação com aqueles com concentrações de 25 (OH) D abaixo de $50 \mathrm{nmol} / \mathrm{L}$. Apenas $5 \%$ dos estudos que analisaram a diversidade da microbiota intestinal, correspondente a um único artigo, relatou que a suplementação de vitamina D alterou de forma significativa a diversidade geral da microbiota intestinal e, em particular, aumentou a abundância relativa de Bacteroidetes, dos filos Verrucomicrobia, Actinobacteria e diminuiu a abundância relativa de Firmicutes. Além de favorecer um enterótipo dominado por Bacteroides em relação ao Prevotella, sendo que este último é considerado um patobionte intestinal (Singh et al., 2020). Dessa maneira, independentemente do percentil de diversidade microbiana, ambos estudos indicam que a deficiência de vitamina D pode favorecer um ambiente apropriado para o estabelecimento de patógenos oportunistas, que causam disfunções na barreira intestinal, propiciando a translocação bacteriana do patógeno, infecção e inflamação sistêmica.

\subsection{Os níveis de vitamina $D$ e os impactos sobre a inflamação intestinal}

Na presente revisão, $50 \%$ dos artigos obtiveram resultados acerca dos efeitos da vitamina D ou da deficiência da mesma sobre a inflamação intestinal. No geral, grupos deficientes de vitamina D (geralmente níveis <30nmol/L) obtiveram níveis mais elevados de citocinas pró-inflamatórias e antiinflamatórias quando comparados a grupos suficientes de vitamina D (geralmente níveis >50nmol/L). A exemplo de Zhou et al. (2020), onde a deficiência de vitamina D em camundongos com câncer colorretal aumentou deterioração da inflamação causada pelo câncer, em comparação com o grupo controle. No entanto, a condição geral dos camundongos melhorou após a suplementação de vitamina D (com 1500 ou 3000 IU vitamin D3/kg). Semelhante ao estudo de $\mathrm{Su}$ et al. (2016), que associou piores graus de esteatose à deficiência de 25-OH $\mathrm{VD}_{3}$ plasmático, assim como o grau de inflamação sistêmica e da integridade do revestimento da mucosa ileal. Além disso, foi verificado um crescimento de $H$. hepaticus nos grupos deficientes de vitamina D e supressão de Akkermansia muciniphila. De acordo com as análises, a vitamina D tem um efeito regulador de probióticos intestinais, a exemplo de Akkermansia muciniphila, bactéria que melhora a permeabilidade intestinal por aumentar a espessura da camada de muco da mucosa intestinal, ajudando na integridade da barreira do cólon. Sendo assim, quando suprimida, a integridade epitelial é prejudicada.

Nakaoka et al. (2018) descreveu um mecanismo diferente ao verificar que uma dieta rica em gordura com restrição de vitamina D regulou negativamente as expressões de mRNA das isozimas fosfatase alcalina intestinal (IAP) no duodeno de modelos animais menopausados. A IAP controla a inflamação induzida por endotoxinas bacterianas ao desfosforilar o lipopolissacarídeo, sendo um fator de defesa da mucosa intestinal. Associado a isso, segundo Ooi et al. (2013) a vitamina D e o VDR impedem o Th1, Th17 e a produção de citocinas inflamatórias no trato gastrointestinal, reduzindo a inflamação no intestino e controlando a disbiose. Nesse sentido, na ausência ou baixa expressão do VDR ou na deficiência de produzir 1,25 $(\mathrm{OH})_{2} \mathrm{D}_{3}$, a inflamação desregulada do intestino resulta em um ambiente que suporta a expansão de bactérias no filo Proteobacteria. A expansão do filo Proteobacteria (incluindo os membros da família Helicobacteraceae) compete com os membros benéficos dos filos Firmicutes e Deferribacteres. Assim como no estudo de Chen et al. (2020), onde Proteobacteria foi maior no grupo deficiente de vitamina D $(<30 \mathrm{nmol} / \mathrm{L})$. Desse modo, ambos estudos descrevem aumento da inflamação e quadros clínicos mais graves diante da deficiência de vitamina D, que beneficia um ambiente patogênico e consequentemente, com presença de endotoxinas.

\subsection{A suplementação de vitamina D como fator de proteção intestinal}

Kong et al. (2008) ao usar sistemas de cultura in vitro obteve um aumento dos níveis de proteínas de junção apertada 
ZO-1, claudina-1, claudina-2 e proteína de unção aderente E-caderina após 24 horas de tratamento com 1,25 (OH) 2 D3. Sendo que no estudo de Ooi et al. (2013), camundongos que não conseguiam produzir 1,25 (OH) D (Cyp KO) apresentaram substancialemente menos expressão de E-caderina que os camundongos controles. Os dados analisados sugerem que a vitamina D e o VDR podem participar da preservação e integridade da barreira intestinal ao aumentar o nível de proteínas chaves para a junção apertada do intestino.

A falta de receptores de vitamina D alterou a função das células epiteliais intestinais (células de Paneth), reduzindo a produção de defensinas e lisozima, antimicrobianos que causam alterações na parede celular das bactérias patogênicas, produzindo sua lise. Dessa forma, defeitos do VDR podem prejudicar a imunidade e integridade inata da barreira intestinal, favorecendo os efeitos inflamatórios e modificações da microbiota intestinal (Wu et al., 2020). No entanto, a suplementação de 1,25 $(\mathrm{OH})$ 2D3 atenuou a permeabilidade paracelular induzida pela infecção por Escherichia coli invasiva aderente e redistribuição de proteínas de junção (Assa et al., 2015). Semelhante ao estudo de Garg et al. (2018), onde a reposição de vitamina D em uma dose de 40.000 UI semanalmente durante 8 semanas reduziu marcadores de inflamação intestinal, como a calprotectina fecal em pacientes com colite ulcerativa ativa deficientes de vitamina D. Dessa maneira, os registros revelam que não só a suplementação de VD é necessária para melhora das inflamações locais e sistêmicas, mas também a expressão e sinalização adequada dos receptores de vitamina D. Por fim, todos os casos obtiveram melhora na permeabilidade intestinal ou melhora dos sintomas após suplementação de vitamina $\mathrm{D}$ em doses recomendadas.

\section{Conclusão}

Com base na análise dos manuscritos que comporam essa revisão sistemática, os dados relatam que níveis suficientes de vitamina D favorecem a presença de bactérias benéficas/probióticos (por exemplo, Lactobacillus, cropococcus, Bacteroidetes e Akkermansia muciniphila) e níveis insuficientes estão associados ao estabelecimento de patobiontes no ambiente intestinal (por exemplo, Prevotella, Escherichia, Candidatus blochmannia e Enterobacter). Além disso, foi demonstrada uma tendência de níveis elevados de citocinas inflamatórias e diminuição da permeabilidade intestinal em níveis deficientes de vitamina D. No entanto, pacientes que fizeram suplementação com vitamina D obtiveram melhora na integridade da barreira intestinal, diminuição de marcadores inflamatórios e resolução dos sintomas intestinais. Sendo assim, diante dos dados disponíveis, manter níveis séricos suficientes de vitamina D (>50nmol/L) favorecem a saúde intestinal, possibilitando um enterótipo dominado por probióticos, diminuição de marcadores inflamatórios, proteção da integridade da barreira intestinal e prevenção e tratamento de inflamações intestinais e sistêmicas. Porém, essa revisão verificou que não apenas a presença ou deficiência de vitamina D interferiu nos resultados obtidos, mas também o seu metabolismo; disponibilidade; infecções e patologias pregressas; presença, expressão e sinalização do VDR. Para uma melhor definição das doses de suplementação e dos níveis plasmáticos adequados de vitamina $\mathrm{D}$, faz-se necessário maiores investimentos em estudos clínicos randomizados em humanos, com padronização de doses e periodicidade, bem como em pesquisas originais que investiguem os mecanismos moleculares envolvidos.

\section{Referências}

Assa, A., Vong, L., Pinnell, L. J, Rautava, J., Avitzur, N., Johnson-Henry, K. C., \& Sherman, P. M. (2015). A deficiência de vitamina D predispõe à disfunção da barreira induzida por Escherichia coli invasiva aderente e lesão experimental do cólon. Doenças inflamatórias do intestino , 21 (2), $297-306$.

Assa, A., Vong, L., Pinnell, L. J., Avitzur, N., Johnson-Henry, K. C., \& Sherman, P. M. (2014). Vitamin D deficiency promotes epithelial barrier dysfunction and intestinal inflammation. The Journal of infectious diseases, 210(8), 1296-1305.

Científico, C., \& de Paula, L. C. P. Hipovitaminose D em pediatria: recomendações para o diagnóstico, tratamento e prevenção.

Chen, D., Li, Y., Sun, H., Xiao, M., Zhang, R. L., Qiu, L., \& Qian, J. M. (2020). Correlation between Vitamin D Status and Gut Microbiota in Patients with Inflammatory Bowel Disease. Zhongguo yi xue ke xue Yuan xue bao. Acta Academiae Medicinae Sinicae, 42(6), 740-748.

Claudio Gonçalves de Castro, L. (2011). O sistema endocrinológico vitamina D The vitamin D endocrine system. In Arq Bras Endocrinol Metab. 55. 
de Oliveira, G. L. V., Leite, A. Z., Higuchi, B. S., Gonzaga, M. I., \& Mariano, V. S. (2017). Intestinal dysbiosis and probiotic applications in autoimmune diseases. In Immunology (152, 1-12). Blackwell Publishing Ltd. https://doi.org/10.1111/imm.12765

Dos Santos Moraes, M., Peres Dos Santos Oliveira, L., Carvalho Furtado, C. De, \& Gaspar Gonzalez, F. (2017). Efeitos funcionais dos probióticos com ênfase na atuação do kefir no tratamento da disbiose intestinal resumo functional effects os probiotics with emphasis on kefir's action in the treatment of intestinal disbiosis. In revista unilus ensino e pesquisa $v$ (vol. 37). Http://revista.lusiada.br/index.php/ruep

Estrela, C. (2018). Metodologia científica: ciência, ensino, pesquisa. Artes Médicas.

Garg, M., Hendy, P., Ding, J. N., Shaw, S., Hold, G., \& Hart, A. (2018). The effect of vitamin D on intestinal inflammation and faecal microbiota in patients with ulcerative colitis. Journal of Crohn's and Colitis, 12(8), 963-972.

Gominak, S. C. (2016). Vitamin D deficiency changes the intestinal microbiome reducing B vitamin production in the gut. The resulting lack of pantothenic acid adversely affects the immune system, producing a "pro-inflammatory" state associated with atherosclerosis and autoimmunity. Medical hypotheses, 94 , 103107.

Jin, D., Wu, S., Zhang, Y. G., Lu, R., Xia, Y., Dong, H., \& Sun, J. (2015). Lack of vitamin D receptor causes dy sbiosis and changes the functions of the murine intestinal microbiome. Clinical therapeutics, 37(5), 996-1009.

Kanhere, M., He, J., Chassaing, B., Ziegler, T. R., Alvarez, J. A., Ivie, E. A., \& Tangpricha, V. (2018). A suplementação de vitamina D3 em bolus semanal tem impacto sobre a microbiota intestinal e das vias aéreas em adultos com fibrose cística: um ensaio clínico duplo-cego, randomizado e controlado por placebo. The Journal of Clinical Endocrinology \& Metabolism , 103 (2), 564-574.

Kong, J., Zhang, Z., Musch, M. W., Ning, G., Sun, J., Hart, J., \& Li, Y. C. (2008). Novel role of the vitamin D receptor in maintaining the integrity of the intestinal mucosal barrier. American Journal of Physiology-Gastrointestinal and Liver Physiology, 294(1), G208-G216.

Marques, C., Dantas, A., Fragoso, T., \& Duarte, Â. (2010). A importância dos níveis de vitamina D nas doenças autoimunes. https://www.scielo.br/j/rbr/a/5BcvSsQGhJPXXD8Q9Pzff8H/?lang=pt

Naderpoor, N., Mousa, A., Arango, L. F. G., Barrett, H. L., Nitert, M. D., \& de Courten, B. (2019). Effect of vitamin D supplementation on faecal microbiota: A randomised clinical trial. Nutrients, 11(12). https://doi.org/10.3390/nu11122888

Nakaoka, K., Yamada, A., Noda, S., \& Goseki-Sone, M. (2018). Vitamin D-restricted high-fat diet down-regulates expression of intestinal alkaline phosphatase isozymes in ovariectomized rats. Nutrition research, 53, 23-31.

Ooi, J. H., Li, Y., Rogers, C. J., \& Cantorna, M. T. (2013). A vitamina D regula o microbioma intestinal e protege camundongos da colite induzida por sulfato de sódio dextrana. The Journal of Nutrition , 143 (10), 1679-1686.

Pereira, A. S., Shitsuka, D. M., Parreira, F. J., \& Shitsuka, R. (2018). Metodologia da pesquisa científica.

Robles-Vera, I., Callejo, M., Ramos, R., Duarte, J., \& Perez-Vizcaino, F. (2019). Impact of vitamin D deficit on the rat gut microbiome. Nutrients, 11(11), 2564.

Schäffler, H., Herlemann, DP, Klinitzke, P., Berlin, P., Kreikemeyer, B., Jaster, R., \& Lamprecht, G. (2018). A administração de vitamina D leva a uma mudança na composição bacteriana intestinal em pacientes com doença de Crohn, mas não em controles saudáveis. Journal of digestive disease , 19 (4), $225-234$.

Singh, P., Rawat, A., Alwakeel, M., Sharif, E., \& al Khodor, S. (2020). The potential role of vitamin D supplementation as a gut microbiota modifier in healthy individuals. Scientific Reports, 10(1).

Su, D., Nie, Y., Zhu, A., Chen, Z., Wu, P., Zhang, L., \& Han, Y. P. (2016). A sinalização da vitamina D por meio da indução de defensinas de células paneth mantém a microbiota intestinal e melhora os distúrbios metabólicos e a esteatose hepática em modelos animais. Fronteiras em fisiologia , 7 , 498.

Weiss, G. A., \& Hennet, T. (2017). Mechanisms and consequences of intestinal dysbiosis. In Cellular and Molecular Life Sciences (74, 2959-2977). Birkhauser Verlag AG. https://doi.org/10.1007/s00018-017-2509-x

Wu, P., Zhang, R., Luo, M., Zhang, T., Pan, L., Xu, S., \& Han, Y. P. (2020). A 25-hidroxilação prejudicada da vitamina D na lesão hepática suprime as defensinas das células Paneth intestinais, levando à disbiose intestinal e fibrogênese hepática. American Journal of Physiology-Gastrointestinal and Liver Physiology, 319 (6), G685-G695.

Yatsunenko, T., Rey, F. E., Manary, M. J., Trehan, I., Dominguez-Bello, M. G., Contreras, M., Magris, M., Hidalgo, G., Baldassano, R. N., Anokhin, A. P., Heath, A. C., Warner, B., Reeder, J., Kuczynski, J., Caporaso, J. G., Lozupone, C. A., Lauber, C., Clemente, J. C., Knights, D., \& Gordon, J. I. (2012). Human gut microbiome viewed across age and geography. In Nature. 486, 222-227. https://doi.org/10.1038/nature11053

Zhou, X., Chen, C., Zhong, Y. N., Zhao, F., Hao, Z., Xu, Y., \& Yin, X. (2020). Effect and mechanism of vitamin D on the development of colorectal cancer based on intestinal flora disorder. Journal of gastroenterology and hepatology, 35(6), 1023-1031. 